\title{
Ordinary users, precursory users and experts in the anticipation of future needs: evaluation of their contribution in the elaboration of new needs in energy for housing
}

\author{
Antoine MARTIN ${ }^{\mathrm{a}}$, Marie-France AGNOLETTI ${ }^{\mathrm{a}}$ and Eric BRANGIER ${ }^{\mathrm{a}}$ \\ ${ }^{a}$ Université de Lorraine, PErSEUs, F-57000 Metz, France
}

\begin{abstract}
With the growing emergence of ergonomic intervention aiming at designing future artefacts, needs analysis is extending to the anticipation of future needs. Both precursory users and experts are known for their deep knowledge of the studied field. In this study, we conducted 36 needs anticipation interviews with ordinary users, precursory users and experts, in order to determine the contribution of each profile to the identification of future needs. The lexical and manual analysis of the interviews shows that the precursory users' speech is the most valuable in terms of both richness and novelty. The discourse of the experts is also richer and more original than that of the ordinary users and differs from that of the precursory users: professional-based for the experts and experiencebased for the precursory users. We therefore recommend the inclusion of both experts and precursory users in the need's analysis and anticipation phase.
\end{abstract}

\section{Keywords}

Precursory users; Needs analysis and anticipation; Prospective ergonomics

\section{Introduction}

User needs analysis is recognized as a critical step in artefact (product, technology, service, organisation or system) design, as it promotes cheaper solutions that are better adapted to users. To assist design in the early stages of innovation projects, it is therefore necessary to take a prospective approach which aims at anticipating future needs related to future artefacts, to enrich designers' and stakeholders' representation of users. One of the main issues for prospective ergonomics 
is therefore to define methods for identifying current and future users' needs, to create artefacts that are both new and adapted.

The purpose of this article is to explore the contribution made by ordinary users, precursory users and experts to the needs anticipation phase, using the needs anticipation interview (a method which is assumed to make needs analysis and anticipation possible). Interviews took place in the context of a study applied to the field of energy for housing.

Firstly, we describe the main methods and issues related to the need's analysis phase and continue by describing the obstacles encountered when trying to anticipate needs and the ways in which these obstacles can be overcome. We then present the needs anticipation interview method and close this theoretical part by describing the role of precursory users and experts in the anticipation of needs. Secondly, we present the study we carried out, using the needs anticipation interview method with ordinary users, precursory users and experts. We conclude by discussing the contributions of our main results to prospective ergonomics methods and to the energy for housing field.

\subsection{Needs analysis and anticipation}

It is common in the user-centred design process to start with a user's needs analysis phase (Barré et al., 2018; French, 1985; International Organization for Standardization, 2019; Loup-Escande et al., 2014; Pahl et al., 2007). Identification of users' needs is supported by traditional methods such as functional analysis, observation, interview and focus group. This step aims at enriching the representation that designers have of users, to enable them to design solutions that meet users' needs better and that are more usable and accepted (Loup-Escande et al., 2014). Thus, it allows designers to offer higher-quality solutions with less expense (Barré et al., 2018). 
Upstream inclusion of user's needs is also known to encourage disruptive innovation (Jaruzelski et al., 2014).

Nevertheless, the growing demand for the design of future artifacts makes it necessary to work on users future needs in order to allow the designer to design artifacts that will be used in the future and that will be adapted to their users (Barré et al., 2018; Bourgeois-Bougrine et al., 2018; Brangier et al., 2017; Loup-Escande et al., 2013). This is the objective to which prospective ergonomics (Brangier \& Robert, 2014; Robert \& Brangier, 2012), is intended to contribute. It proposes a two-step approach that consists first of anticipating future needs and then of defining preliminary ideas for future artefacts that meet these needs.

Future needs anticipation - the premature identification of future user needs requires users or designers to project uses of an artefact into the future. This process is complicated for multiple reasons:

- Users find have difficulties to represent an artifact they don't know or that doesn't exist (Anastassova et al., 2007; Anastassova \& Mayora-Ibarra, 2009; Barré et al., 2018; Bourgeois-Bougrine et al., 2018; Loup-Escande et al., 2014; Petiot \& Yannou, 2004)

- Users find it difficult to imagine new needs (Spérandio, 2001 in Anastassova, 2006).

- Users find it difficult to project themselves into the future (Barré et al., 2018; Bourgeois-Bougrine et al., 2018; Trope \& Liberman, 2003, 2010);

- Designers have difficulties to represent the real needs of users, as they rely on a hypothetical representation of the interaction between the user and the artifact (Hassenzahl, 2018; Norman, 1988); 
- Designers are the victims of design fixation, they over-rely on their representation of the actual artefact and users, which limits their ability to represent novel needs (Jansson \& Smith, 1991; Youmans \& Arciszewski, 2014), the use of retrospective methods of needs analysis has notably been pointed out (Nelson et al., 2013);

- Designers are focused on technical development rather than user needs (Anastassova, 2006).

Several proposals to circumvent these difficulties and to stimulate the anticipation of needs have been made. In the same way as Buisine et al. (2018), we consider those which aim at inventing new needs (creation paradigm), and those which aim at identifying the forms they can take (discovery paradigm). The first relies on creativity methods (e.g. persona, creativity session etc.) to foster the expression of new needs, while the second is based on methods that are assumed to help users represent their possible interactions with an artefact (e.g. simulation, role playing etc.) or to project themselves into a future situation (e.g. future oriented cognition) to improve the collection of future needs (Colin \& Martin, 2019) or products ideas (Frederiks et al., 2019). Brangier et al. (2019) suggest that in addition to methods for anticipating future needs, there are individuals who have a greater capacity to produce future representations (see section 1.3).

Given these elements, to support the elicitation of future needs, we selected an interview format designed to favour the depiction of the future, applied to individuals with supposed endowed capacities of future representations and creativity.

\subsection{Needs anticipation interview}

The Needs anticipation interview method is derived from future-oriented interviews conducted by Nguyen and Cahour (2014) on mobility and by Brangier et al. 
(2019) on the travel industry. It consists of constructing a situation of verbal production of future needs. This method aims at producing knowledge on future needs, by promoting the mental construction of a future representation, and by priming with negative and positive experiences related to activities in the targeted field. For this, the method relies on knowledge of future oriented cognition - the human cognitive ability to project into the future - which is known to be based on past episode memory (D’Argembeau, 2016; Hollis-Hansen et al., 2019; Miloyan et al., 2019). Therefore, to encourage future projections and identify positive and negative experience related to the activity, the interview starts by focusing on experience. The interview then focuses on future experience, first by making participants build an embodied representation of the future, and then by having the participant ideate on future needs freely, using the positive and negative experiences previously detected as a trigger. It is therefore both a matter of detecting needs and making them evolve into a mental representation of the future and of creating new ideas of needs adapted to this representation of the future. Data collected during these interviews can be used by ergonomists to:

- Produce media for designers to supply the design process and enrich their representations of the future users, more specifically about presents and futures needs, activity and experience;

- Create a catalogue of solutions inspired by the corpus.

\subsection{Precursory users and experts in needs anticipation}

As stated above, users and designers are limited in their capacity to envision future uses of an artefact. However, they are individuals who are believed to have better abilities to picture the future: experts and precursory users.

Experts have a professional expertise in the targeted field acquired through their training and professional experience. This expertise is the experiential and theoretical 
knowledge they use to make relevant and elaborate decisions (Brangier et al., 2019; Visser \& Falzon, 1988). This expertise can be scientific, technical or organisational. Experts have been documented to have an elaborated representation of the future of the targeted field, and to be creative (Brangier et al., 2019). They are recognized as legitimately representing a community (Bastien et al., 2009). Experts have already been mobilized to identify and anticipate user needs using the expert staff method (Bastien et al., 2009) and the needs anticipation interview method (Brangier et al., 2019). However, this approach raises the question of the experts' conceptual model of usage. Indeed, experts, and particularly technical experts, have a conceptual model of usage which relates to the designer's model (Norman, 1988) or designer perspective (Hassenzahl, 2018): it is the representation of the probable or desired use of the object by the user, a hypothetical representation which does not necessarily correspond to reality.

To access the users' conceptual model of usage, it seems obvious to involve them in this early stage, but it appears that the limitations of users regarding the anticipation of needs are strong. We therefore propose to involve special users: the precursory users. They are often confused with the concept of lead users, which is more strictly speaking a method (Lilien et al., 2002). Used in the fields of marketing and innovation management, the method was introduced by Von Hippel in 1986. It consists of involving users who are "at the leading edge" of the targeted market or related market in the design process (von Hippel, 1986), to collect needs and ideas of solutions (Lilien et al., 2002). This method is supported by the fact that these individuals are:

- experiencing in advance what the rest of the users will experience later (Brem et al., 2018; von Hippel, 1986);

- creative (Faullant et al., 2012; Lilien et al., 2002; von Hippel, 1986);

- strongly committed to innovation (Lilien et al., 2002). 
The method makes it possible to both collect needs and generate ideas of solutions, and unfolds in 4 phases (Lilien et al., 2002). First, a group is formed in the company to specify the objectives of the project. Secondly, this team then identifies strong trends in the market. Thirdly, users "at the leading edge of the market" join the working group to share the needs and solutions they encounter. Finally, the entire working group works at improving the solutions set out in the previous phase.

For the purpose of clarity, we propose to differentiate the lead user which is a method, and the precursory users which can be defined as individuals who experience activities or artefacts that are identified as being precursory or prospective, and not necessarily highly committed to innovation. Their expertise is related to their nonprofessional experience and knowledge. It is built on knowledge and experience related to domestic activities and artefacts. Thus, precursory users can be considered as use experts, whose representations of the field, activities and artefacts are more advanced than those of ordinary users. Precursory users should therefore be useful in the needs anticipation phase, as they can detect needs that are not yet felt by ordinary users, and through their expertise of use, they develop rich representations of the domain, activities and artefacts, which can provide them with the ability to anticipate future needs.

Robert et al. (2019) and Buisine et al. (2018) have also highlighted the potential benefits of including precursory users in the need's anticipation phase. While the ability to identify needs not felt by ordinary users and the ability to generate solutions have already been demonstrated among participants in the lead user method (Lilien et al., 2002), it remains to be seen what is the capacity of lead users to identify needs not felt by ordinary users and to imagine future needs, and to identify their specificities compared to experts. 


\subsection{Energy for housing and users}

Needs analysis is an important element in the design of a home energy system. In fact, the mismatch between energy systems and user needs, may not only be the cause of dissatisfaction for the inhabitant but may also have deleterious consequences on the efficiency of the system. For instance, experiments to reduce energy consumption through energy efficiency buildings and equipment have been conducted, their results show that expected reduction in consumption has not been observed (Blaise \& Glachant, 2019; Sidler, 2011). This gap is explained by a lack of compliance from users with instructions on the use of the building and equipment (Zélem et al., 2013). Moreover, Revell and Stanton (2017) have shown that inhabitants can increase their energy consumption even when they seek to reduce it, when the artefact that support their activity doesn't fits their representation of it.

The literature on energy-related activity in the home refers to domestic activities (e.g. entertainment, air conditioning etc.) that result in energy consumption (Bonnin, 2016; Bovay, 1987; Guibourdenche, 2013; Guibourdenche et al., 2015). In a more minor way, energy consumption management activities (which aim to reduce energy consumption) and energy system management activities (which aim to manage energy production and sale) are observed in individual energy producers (Lahoual \& Fréjus, 2013).

\section{Research questions and hypotheses}

This study attempts to determine the contribution of ordinary users, precursory users and experts to the need's analysis and anticipation phase.

Our first assumption is that the exposure of precursory users to activities and artefacts considered to be precursors allows them to develop early on needs that will be experienced by the majority of users in the future, and to develop elaborate 
representations of the activities, field and artefacts that facilitate their ability to anticipate future needs. Besides that, experts have a rich representation of the domain and are creative, which should facilitate their ability to anticipate future needs.

Our second assumption is that due to the different nature of their expertise, precursory users and experts have different representations of the present and future. Indeed, experts rely on a hypothetical representation of users and their goals are not user-oriented, while precursory users rely on real uses-representation and their goals are user-oriented.

These assumptions led us to the following hypotheses:

- H1: Precursory users and experts needs related discourse may be more novel and adapted than ordinary users:

- H1.1 (Interview lexical cluster): experts and precursory users may mention more original lexical cluster than ordinary users;

- H1.2 (Needs idea fluency): experts and precursory users may generate more ideas in their interview than ordinary users;

- H1.3 (Needs idea originality): experts and precursory users may generate more ideas scored as statistically original in their interview than ordinary users;

- H1.4 (Needs idea novelty): experts and precursory users may generate more ideas scored as novel in their interview than ordinary users;

- $\quad H 1.5$ (Needs idea feasibility): experts and precursory users may generate more ideas scored as feasible in their interview than ordinary users;

- H1.6 (Needs idea relevance): experts and precursory users may generate more ideas scored as relevant in their interview than ordinary users; 
- H2: precursory users and experts may have a different discourse related to present and future needs:

- H2.1 (Interview lexical cluster): experts and precursory users may mention different lexical cluster.

\section{Method}

\subsection{Participants}

A total of 36 participants were involved in this study: 14 precursory users, 11 regular users and 11 experts. They were 12 women and 24 men, aged between 25 and $74($ mean $=43.50$, standard deviation $=14.58)$. The choice of the number of participants is the result of a trade-off between the difficulty of identifying participants (specifically precursory users and experts) and the possibility of carrying out statistics with a perspective of comparison. Precursory users were recruited for their precursory uses in the fields of energy and housing (e.g. energy autarky), experts were recruited for their professional expertise in energy and/or housing fields (e.g. Researcher in Urban Planning and Expert from the Intergovernmental Panel on Climate Change), and regular users were recruited for having no professional expertise or precursory uses in these fields. The precursory uses were defined based on the prospective literature from ADEME (French Environment and Energy Management Agency). Precursory users and experts were identified on social networks, professional social networks and via internet searches. Participants were not paid and gave their informed consent before participating in the study.

\subsection{Material}

Activity maps were used to facilitate verbalization in relation to energy for housing related activities. They were built on the basis of the analysis of literature on 
energy for housing and exploratory interviews related to the use of energy for housing conducted with 9 individual energy producers. These interviews aimed at supplement the relevant literature. They consist of a textual and visual description of human activities related to three topics.

(1) Energy system installation: these are the activities carried out during the installation or renovation of an energy system: make inquiries and design the energy system, convince relatives, finance the energy system, manage its installation, install the energy system, check its compliance and start it up (see Figure 1). 


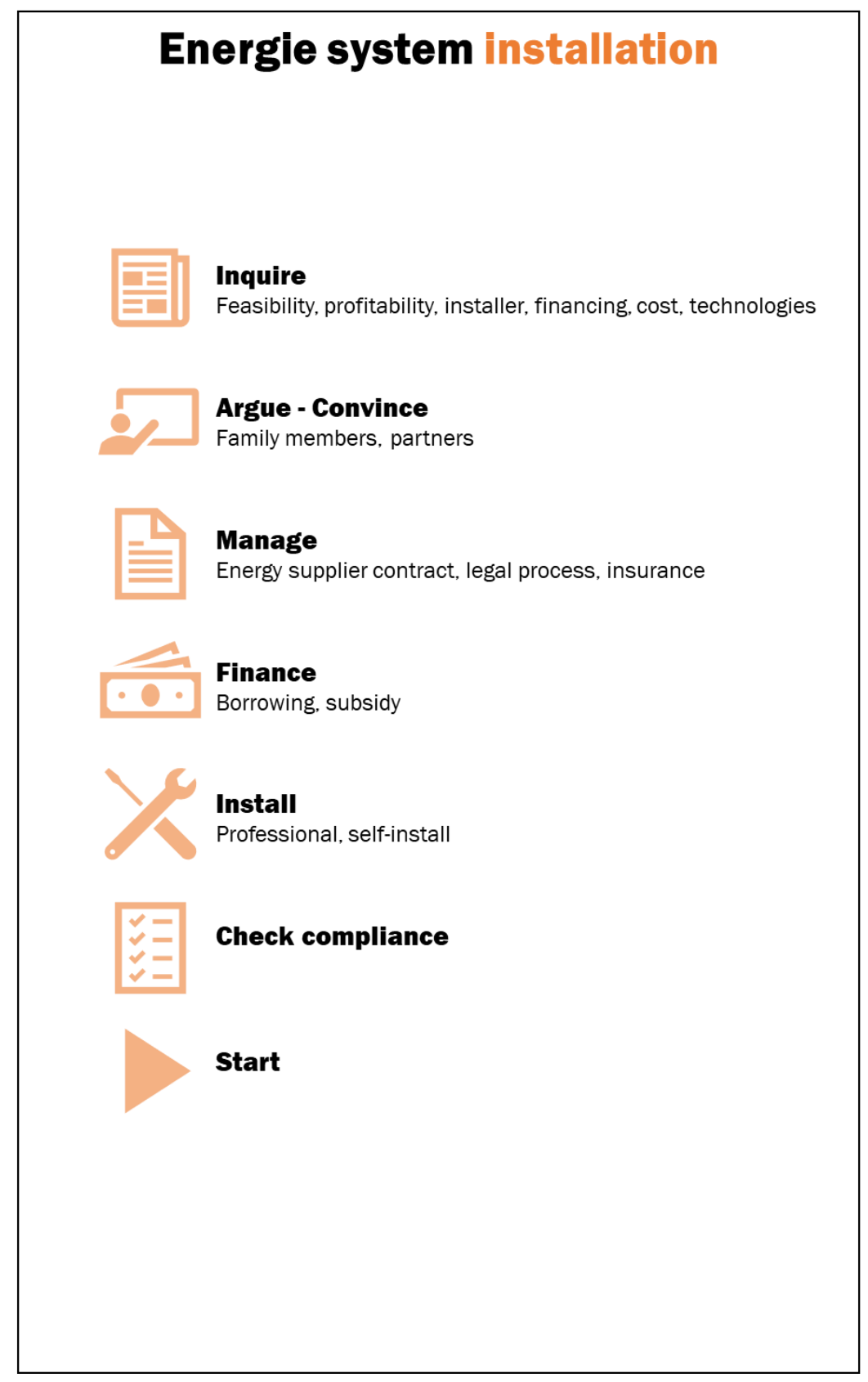

Figure 1: Activity map on (1) Energy system installation topic.

(2) Energy system management: these are activities that are deployed to manage energy supply, energy self-generation, energy storage and energy distribution. These activities include supervision, inspection, maintenance, enhance, pay and sell energy (see Figure 2). 


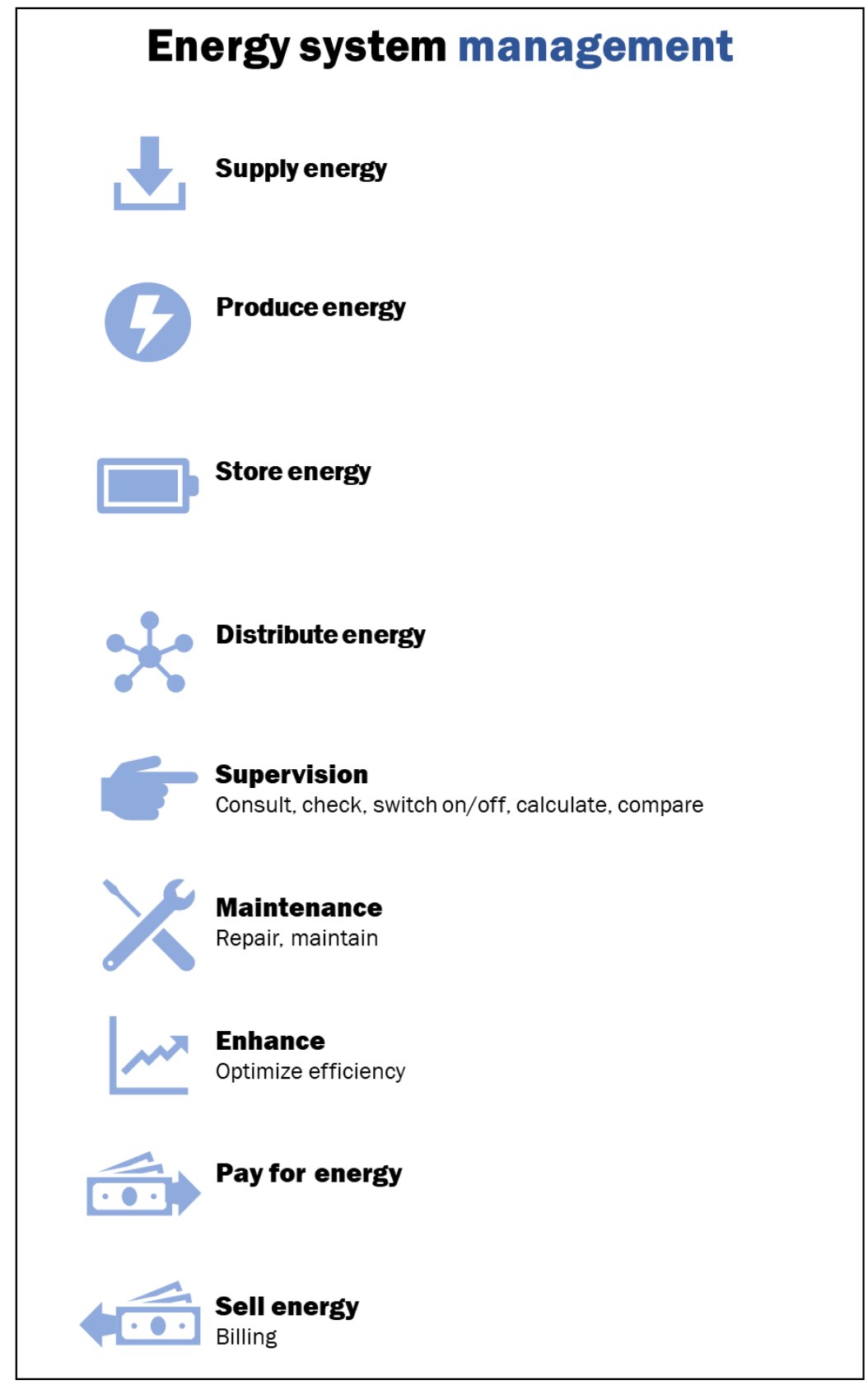

Figure 2: Activity map on (2) Energy system management.

(3) Energy consumption management: these are activities carried out to control energy consumption: check consumption, act on equipment and behaviours (see Figure $3)$. 


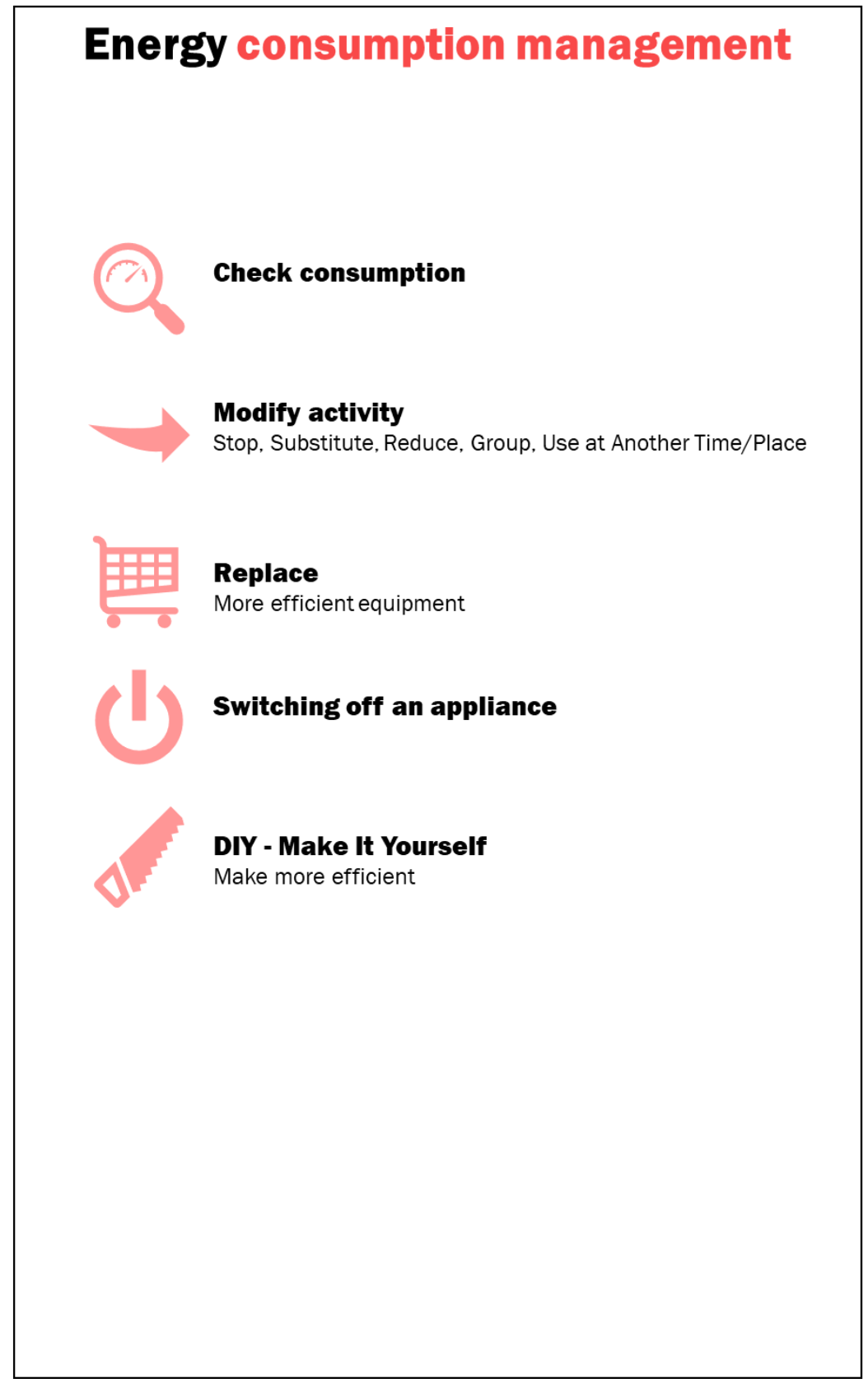

Figure 3: Activity map on (3) Energy consumption management.

\subsection{Procedure}

Needs anticipation interviews were carried out face to face individually. They were recorded using a voice recorder. Interviews were structured into four main steps: 1. Priming: participants were asked to talk freely about energy for housing and related activities, to set the scope of the interview. 
2. Experiences: participants were then asked to verbalize their past experiences of energy for housing, first freely and then using the corresponding activity map. Participants were asked to freely verbalize their experience and then to verbalize their meaningful, positive and negative experience. This step was repeated for each of the 3 topics.

3. Future projection: the interviewer led the participants to project themselves into the future, following future oriented cognition literature recommendations.

After recalling past experiences (D'Argembeau, 2016; Hollis-Hansen et al., 2019; Irish \& Piguet, 2013; Miloyan et al., 2019; Schacter et al., 2007), the projection was made by first asking respondents to describe in a general way their long-term vision of the future to build the general context of future events (Irish \& Piguet, 2013). Participants were then asked to imagine very precisely the place where they would live in this future to develop a future autobiographical context (D'Argembeau \& Van der Linden, 2012; Irish \& Piguet, 2013; Schacter et al., 2007). In order to develop a future as detailed experience as possible (D’Argembeau \& Van der Linden, 2012; Noël et al., 2017), participants were then asked to describe orally in as much detail as possible this representation of the future they imagined themselves living in.

4. Future ideation: the participants were then asked to ideate on the future of each of the three topics. First freely to enrich the topic's future context and to initiate the emergence of future needs, secondly with the corresponding activity map to elaborate and enrich future needs. This step was repeated for each of the 3 topics. Finally, the participants were asked to complete a questionnaire on conventional sociodemographic data and on their perceived expertise in the fields of energy and housing. 


\subsection{Data analysis}

After being transcribed, the collected data was subject to lexical analysis and needs idea analysis, to characterise the contribution of the different profile of participants to the anticipation of future needs. The objective of the lexical analysis was to describe the overall discourse of the different profile of participants, whereas the objective of the need's idea analysis was to allow for the specific study of the needs expressed by the participants.

\subsubsection{Lexical analysis}

We used IraMuTeQ 7.2 to perform the lexical analysis of the textual data corresponding to the interviews. Based on textual statistics (lexical frequencies, cooccurrences, chi2 etc.), lexical analysis is used to assist the identification of the significantly stated lexical clusters and their organization in a discourse. The lexical analysis is recommended by Wolff et al. (2005) to analyse in detail the discourse collected during interviews, for example, of the different actors involved in the design process. To identify the lexical clusters that structure our corpus, we performed a hierarchical cluster analysis on sub-corpuses that corresponds to each profile of participants. In this analysis, text segments are grouped iteratively into classes according to the distribution of words in the corpus, to represent lexical clusters significantly evoked in the corpus.

\subsubsection{Needs idea analysis}

\subsubsection{Needs ideas extraction}

Needs fulfilment is known to be expressed by positive affect and is related to positive experience, while needs dissatisfaction is expressed by negative affect and is related to negative experience (Hassenzahl et al., 2010, 2015; Partala \& Kallinen, 2012; Tuch et al., 2013, 2013). The analysis of user experience verbalization is therefore a way for the ergonomist to access user needs, especially when the activity is not 
observable, which is the case with future needs. In line with this, we extracted from the corpus ideas about elements that support (or could support) a positive user experience (e.g. "I want to talk to my house, I want to say to it: "I'm going to have people in tonight, do not worry, make it good, and not too expensive"") and ideas about elements that lead (or could lead) to a negative user experience (e.g. "I do not think you have sufficient monitoring of your energy production in your home"). Ideas of elements that support a positive user experience are elements that contribute to meet user needs. These are elements on which to rely when designing artefacts. Ideas of elements that lead to a negative user experience correspond to elements that contribute to the dissatisfaction of user needs. These are things to avoid and problems to solve when designing artefacts. We consider that these ideas correspond to the most significant expressions of present and future needs.

To identify these elements from the corpus, a coding grid was constructed. Following an inductive approach, we specify 12 criteria, 6 for elements that support a positive user experience idea and 6 for elements that lead to a negative user experience idea (see Table 1), based on 15 interviews analysis (of the 3 participant profiles). These criteria were then validated by 16 ergonomists, who had to note the relevance of each criterion (whether it is a relevant criterion for identifying identify the verbalisation of the element contributing to the satisfaction of user needs, or whether it is a relevant criterion for identifying the verbalisation of elements contributing to the dissatisfaction of user needs) on a Likert scale of 1 (not adapted at all) to 7 (highly adapted). All criteria were deemed suitable. 


\section{Table 1}

Criteria for identifying ideas of elements that support a positive user experience or lead to a negative user experience.

\begin{tabular}{|c|c|}
\hline $\begin{array}{l}\text { 1. Elements that lead to a negative user } \\
\text { experience }\end{array}$ & $\begin{array}{l}\text { 2. Elements that support a positive user } \\
\text { experience }\end{array}$ \\
\hline 1.1 Enunciation of a source of displeasure & 2.1 Enunciation of a source of pleasure \\
\hline 1.2 Enunciation of a fear & 2.2 Enunciation of a wish \\
\hline 1.3 Enunciation of a source of inefficiency & 2.3 Enunciation of a source of effectiveness \\
\hline 1.4 Enunciation of a difficulty & 2.4 Enunciation of a facilitator element \\
\hline 1.5 Enunciation of an impossibility & 2.5 Enunciation of a new artefact function \\
\hline 1.6 Enunciation of a lack & 2.6 Enunciation of a new artefact \\
\hline
\end{tabular}

After being extracted, the ideas were categorized to identify the original proposition, and finally to identify the needs through the expression of their satisfaction or dissatisfaction.

\subsubsection{Ideas evaluation}

As an initial phase of a design project, the need's analysis and anticipation is considered as a design activity for which we seek needs that are novel and adapted to the future context (Bonnardel, 2012; Bonnardel \& Pichot, 2020), specifically in the context of prospective ergonomics (Brangier \& Robert, 2014; Robert \& Brangier, 2012). In other words, we are looking for ideas of needs that are creative, that is to say which are new, relevant and realistic. To assess the creative quality of interview ideas, we followed the Bonnardel and Pichot method (2020), which relies on the conventional dimensions of fluency and originality (Torrance et al., 1966) in addition to novelty, feasibility and relevance (Dean et al., 2006):

- Fluency: total number of ideas produced;

- Originality: statistical rarity of ideas; 
- Novelty: average of the originality score and the paradigm-changing score of the idea;

- Feasibility: average of the acceptability score and the implementability score of the idea;

- Relevance: average of the applicability score and the effectiveness score of the idea.

Extracted needs idea novelty, feasibility and relevance were scored independently and blind to conditions by first author and an independent judge (ergonomist working in the energy field). Using Likert scales of 1 (strongly agree) to 7 (strongly disagree), judges had to assess:

- The surprising and paradigm-changing quality of ideas (for novelty);

- The acceptable and implementable quality of ideas (for feasibility);

- The applicable and effective quality of ideas (for relevance).

Raters disagreements were resolved by discussion. Inter-rater reliability was calculated using Krippendorff's Alpha (inter-rater reliability test used for ordinal coding) and was acceptable $(\alpha=.77)$.

Extracted needs idea fluency and originality were calculated and for each participant the number of original ideas (ideas rated as more original than average), the number of new ideas (ideas rated as newer than average), the number of feasible ideas (ideas rated as more feasible than average) and the number of relevant ideas (ideas rated as more relevant than average) were calculated.

3 participants (all precursory users) were excluded from the analysis because their interview took place in different conditions. Statistical analyses were then conducted using Jamovi 1.2.16 and JASP 0.12.1. 


\section{Results}

\subsection{Description of the collected data}

Interviews lasted between 56 minutes and 3 hours 38 minutes $($ mean $=106.68$; standard deviation $=33.23$ ) for a total of 59 hours and 25 minutes. There was no difference in the length of the interviews for ordinary users, precursory users and experts $\left(H(2)=3.48 ; p=0.176 ; \varepsilon^{2}=0.109\right)$. After transcribing the interviews and removing the interviewer's interventions, we obtained a corpus of 376819 words for a total of 33534 lines and 581 pages.

\subsection{Lexical analysis: classification of lexical clusters}

To assess the lexical clusters mentioned in the interviews, we ran a hierarchical cluster analysis, which allowed us to identify the significantly mentioned lexicon. This analysis was carried out for each profile of participants, with the same parameters.

\subsubsection{Lexical clusters mentioned by the experts}

Experts' speech is significantly made up of four lexical clusters (see Figure 4):

- Cluster 1 refers to desirable energy systems in its technical (e.g. "solar panels", "smart grid") and organizational (e.g. "large scale") aspects;

- Cluster 3 refers to the expectations of energy professionals and focuses on the new services they have to offer (e.g. "maintenance contract");

- Cluster 2 describes the new challenges for energy professionals (e.g. "adapting to needs", "privacy management");

- Cluster 4 describes the uses of energy (e.g. "heating") and energy consumption management activities (e.g. "reducing heating", "installing sensors"). 


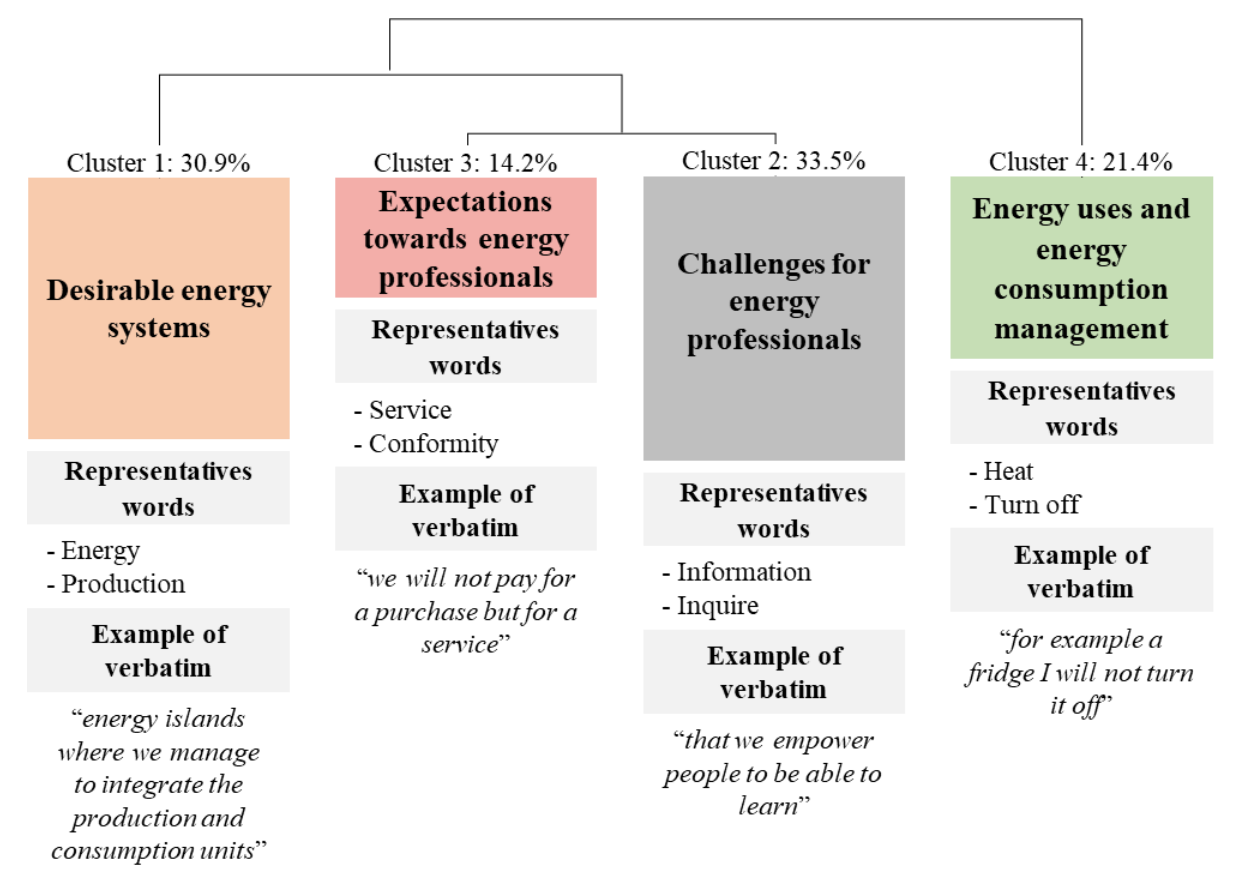

Figure 4: Hierarchical cluster analysis dendrogram of experts' interviews (92.37\% of corpus segments classified) including for each cluster: percentage of speech represented, representatives words and example of verbatim.

\subsubsection{Lexical clusters mentioned by the precursory users}

Precursory users' speech is significantly composed of lexical clusters (see Figure 5):

- Cluster 4 refers to energy consumption management activities (e.g., "turning off appliances", "changing habits") and energy system management activities (e.g., "turning on the battery") performed by users;

- Cluster 3 refers to the uses of energy (e.g. "heating", "cooking"), equipment (e.g. "solar panel") and energy sources (e.g. "wood", "gas", "electricity");

- Cluster 1 refers to the installation of the energy system (e.g. "cost", "convincing your family", "legal approach");

- Cluster 5 refers to desirable energy systems and in particular to their characteristics (e.g. "autonomous", "local");

- Cluster 2 focuses on desirable changes at the individual level (e.g. "getting involved", "empowering"); 
- Cluster 6 focuses on the relationship to society, the state and energy professionals, including access to information and decision-making capacity.

\begin{tabular}{|c|c|c|c|c|c|}
\hline Cluster $4: 17.4 \%$ & Cluster $3: 14.5 \%$ & Cluster 1: $17.9 \%$ & Cluster 5: $14.8 \%$ & Cluster $2 \cdot 177 \%$ & Cluster 6. $17.7 \%$ \\
\hline $\begin{array}{c}\text { Energy } \\
\text { consumption } \\
\text { and system } \\
\text { management }\end{array}$ & Energy uses & $\begin{array}{l}\text { Energy system } \\
\text { installation }\end{array}$ & $\begin{array}{c}\text { Desirable energy } \\
\text { systems }\end{array}$ & $\begin{array}{c}\text { Desirable } \\
\text { changes at the } \\
\text { individual level }\end{array}$ & $\begin{array}{l}\text { Relation to } \\
\text { society, state } \\
\text { and energy } \\
\text { professionals }\end{array}$ \\
\hline $\begin{array}{c}\text { Representatives } \\
\text { words }\end{array}$ & $\begin{array}{l}\text { Representatives } \\
\text { words }\end{array}$ & $\begin{array}{c}\text { Representatives } \\
\text { words }\end{array}$ & $\begin{array}{c}\text { Representatives } \\
\text { words }\end{array}$ & $\begin{array}{c}\text { Representatives } \\
\text { words }\end{array}$ & $\begin{array}{c}\text { Representatives } \\
\text { words }\end{array}$ \\
\hline $\begin{array}{l}\text { - Battery } \\
\text { - Turn off }\end{array}$ & - Wood & $\begin{array}{l}\text { - Install } \\
\text { - Energy provider }\end{array}$ & $\begin{array}{l}\text { - Energy } \\
\text { - Production }\end{array}$ & $\begin{array}{l}\text { - People } \\
\text { - Think }\end{array}$ & $\begin{array}{l}\text { - Answer } \\
\text { - Information }\end{array}$ \\
\hline $\begin{array}{l}\text { Example of } \\
\text { verbatim }\end{array}$ & $\begin{array}{l}\text { Example or } \\
\text { verbatim }\end{array}$ & $\begin{array}{l}\text { Example of } \\
\text { verbatim }\end{array}$ & $\begin{array}{c}\text { Example of } \\
\text { verbatim }\end{array}$ & $\begin{array}{l}\text { Example of } \\
\text { verbatim }\end{array}$ & $\begin{array}{l}\text { Example of } \\
\text { verbatim }\end{array}$ \\
\hline $\begin{array}{l}\text { "solar panels } \\
\text { should not be } \\
\text { allowed to take the } \\
\text { sun if they are not } \\
\text { connected to a } \\
\text { regulator" }\end{array}$ & $\begin{array}{l}\text { thermal panels } \\
\text { which are } \\
\text { connected to the } \\
\text { water heater" }\end{array}$ & $\begin{array}{c}\text { "It costs them less } \\
\text { to install" }\end{array}$ & $\begin{array}{c}\text { "connect the places } \\
\text { of production to the } \\
\text { place where there is } \\
\text { consumption" }\end{array}$ & $\begin{array}{l}\text { "I hope that people } \\
\text { will be able to } \\
\text { better adapt their } \\
\text { consumption" }\end{array}$ & $\begin{array}{l}\text { "they will extract } \\
\text { this data from } \\
\text { information to } \\
\text { respond to the } \\
\text { global problem" }\end{array}$ \\
\hline
\end{tabular}

Figure 5: Hierarchical cluster analysis dendrogram of precursory users' interviews (98.54\% of corpus segments classified) including for each cluster: percentage of speech represented, representatives words and example of verbatim.

\subsubsection{Lexical clusters mentioned by the ordinary users}

Ordinary users' speech is significantly structured into four lexical clusters (see Figure 6):

- Cluster 2 refers to desirable changes at the individual level (e.g. "optimize", "realize");

- Cluster 1 refers to desirable energy systems and in particular their characteristics (e.g. "local", "clean");

- Cluster 3 refers to the services expected from energy professionals (e.g. "inform", "install");

- Cluster 4 refers to the uses of energy (e.g., "heating") and energy consumption management activities (e.g., "purging heating"). 


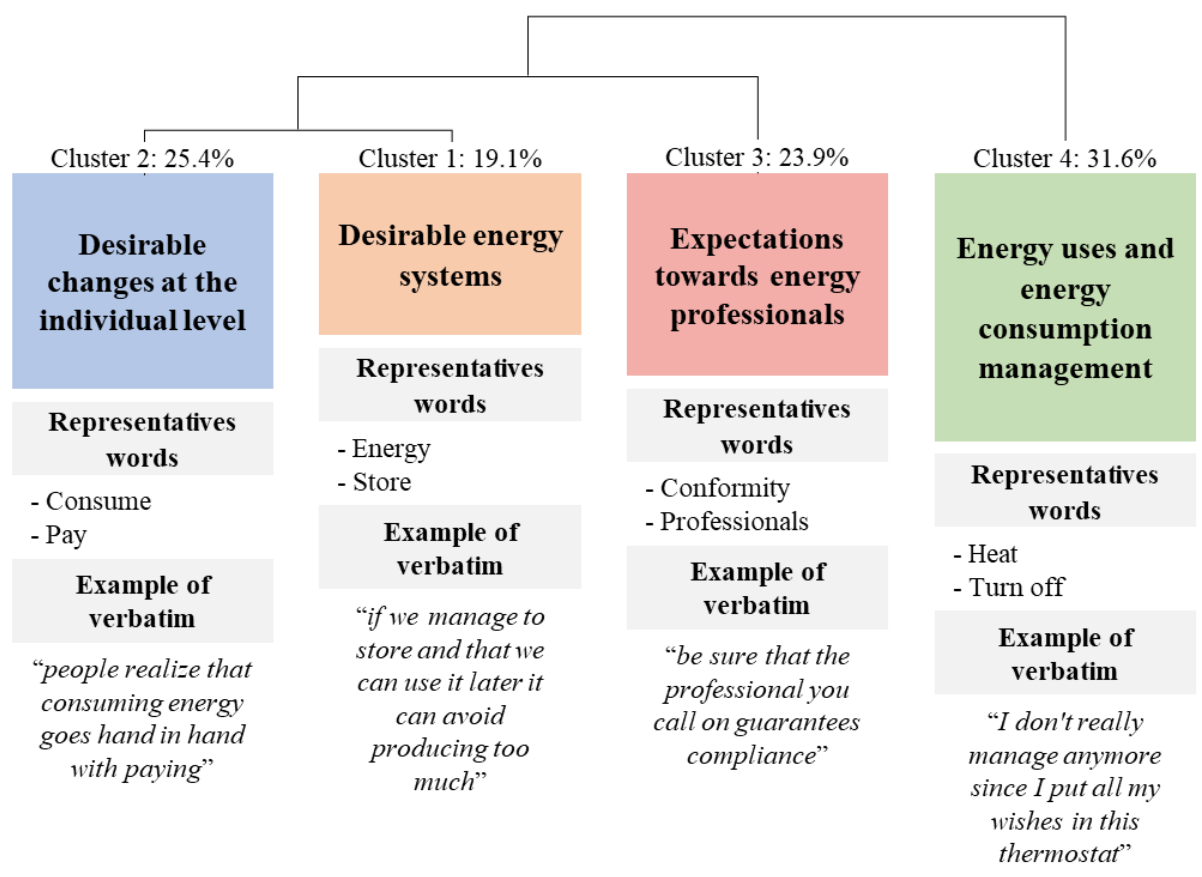

Figure 6: Hierarchical cluster analysis dendrogram of ordinary users' interviews (98.02\% of corpus segments classified) including for each cluster: percentage of speech represented, representatives words and example of verbatim.

\subsubsection{Comparison of the lexical clusters mentioned by each profile of participants}

If we compare the lexical clusters evoked by each profile (see Table 2), we notice that experts mention only one lexical cluster which is not mentioned by the other profiles (Challenges for energy professionals). Precursory users mention three lexical cluster which are not mentioned by the other profiles (Energy system management, Energy system installation, Relation to society and state and energy professionals). They have one shared lexical cluster with experts (Expected from energy professionals) and one with the ordinary users (Desirable changes at individual level). Ordinary users' lexical cluster are all mentioned by the other profiles. We also observe that all 3 profiles have the following lexical cluster in common: energy uses, energy consumption management and desirable energy systems. 


\section{Table 2}

Lexical clusters mentioned by ordinary users, precursory users and experts.

\begin{tabular}{r|c|c|c}
\hline \multicolumn{1}{c|}{ Lexical clusters } & $\begin{array}{c}\text { Ordinary } \\
\text { users }\end{array}$ & $\begin{array}{c}\text { Precursory } \\
\text { users }\end{array}$ & Experts \\
\hline Desirable energy systems & $\mathrm{X}$ & $\mathrm{X}$ & $\mathrm{X}$ \\
\hline Energy uses & $\mathrm{X}$ & $\mathrm{X}$ & $\mathrm{X}$ \\
\hline Energy consumption management & $\mathrm{X}$ & $\mathrm{X}$ & $\mathrm{X}$ \\
\hline Expectations towards energy professionals & $\mathrm{X}$ & & $\mathrm{X}$ \\
\hline Desirable changes at the individual level & $\mathrm{X}$ & $\mathrm{X}$ & \\
\hline Challenges for energy professionals & & & $\mathrm{X}$ \\
\hline Energy system management & & $\mathrm{X}^{*}$ & \\
\hline Energy system installation & & $\mathrm{X}^{*}$ & \\
\hline Relation to society, state and energy professionals & & $\mathrm{X}^{*}$ & \\
\hline
\end{tabular}

* Original lexical cluster

These analyses allow us to indicate that precursory users evoke more lexical cluster and more original lexical cluster than ordinary users and experts, the latter also evoking one original lexical cluster. We also observed that the precursory users have the most pragmatic discourse in relation to activities related to energy in the home (e.g. Energy system installation), while the experts have a discourse that refers more to professional aspects (e.g. Challenges for energy professionals). These results are consistent with our hypotheses that experts and precursory users mention more original lexical clusters than ordinary users (H1.1) and that experts and precursory users mention different lexical clusters (H2.1).

\subsection{Needs idea analysis}

In all, 807 verbatims corresponding to needs ideas were extracted, for a total of 231 original needs ideas. To verify the normality of data, we ran a Shapiro-Wilk test which showed that not all variables met the assumption of normality. For this reason, 
we used the nonparametric Kruskal-Wallis test, to perform comparisons of scores between profiles.

Our analyses did not show any significant differences for (see Table 3):

- Idea fluency scores in topic $1\left(H(2)=1.427, p=0.490, \varepsilon^{2}=0.045\right)$ and in topic $3\left(H(2)=1.871, p=0.392, \varepsilon^{2}=0.058\right)$

- Number of original ideas in topic $1\left(H(2)=0.308, p=0.857, \varepsilon^{2}=0.009\right)$, topic $2\left(H(2)=3.978, p=0.137, \varepsilon^{2}=0.123\right)$ and in topic $3(H(2)=1.199, p=0.549$, $\left.\varepsilon^{2}=0.036\right)$

- Number of novel ideas in topic $1\left(H(2)=2.3768, p=0.305, \varepsilon^{2}=0.074\right)$ and in topic $3\left(H(2)=0.152, p=0.927, \varepsilon^{2}=0.004\right)$;

- Number of feasible ideas in topic $1\left(H(2)=1.636, p=0.441, \varepsilon^{2}=0.051\right)$, topic $2\left(H(2)=3.831, p=0.147, \varepsilon^{2}=0.112\right)$ and in topic $3(H(2)=0.513, p=0.774$, $\left.\varepsilon^{2}=0.016\right)$

- Number of relevant ideas in topic $1\left(H(2)=1.427, p=0.49, \varepsilon^{2}=0.045\right)$ and in topic $3\left(H(2)=1.871, p=0.392, \varepsilon^{2}=0.058\right)$. 


\section{Table 3}

Kruskal-Wallis test: H statistic (H), degrees of freedom (df), p value ( $p)$ and epsilon squared $\left(\varepsilon^{2}\right)$ for fluency, number of original ideas, number of novel ideas, number of feasible ideas and number of relevant ideas by topic.

\begin{tabular}{|c|c|c|c|c|c|c|c|c|c|c|c|c|}
\hline & \multicolumn{4}{|c|}{$\begin{array}{l}\text { (1) Energy system } \\
\text { installation }\end{array}$} & \multicolumn{4}{|c|}{$\begin{array}{l}\text { (2) Energy system } \\
\text { management }\end{array}$} & \multicolumn{4}{|c|}{$\begin{array}{c}\text { (3) Energy consumption } \\
\text { management }\end{array}$} \\
\hline & $H$ & $d f$ & $p$ & $\varepsilon^{2}$ & $H$ & $d f$ & $p$ & $\varepsilon^{2}$ & $H$ & $d f$ & $p$ & $\varepsilon^{2}$ \\
\hline Fluency & 1.427 & 2 & 0.490 & 0.045 & 6.065 & 2 & $0.048^{*}$ & 0.190 & 1.871 & 2 & 0.392 & 0.058 \\
\hline $\begin{array}{l}\text { Number of } \\
\text { original } \\
\text { ideas }\end{array}$ & 0.308 & 2 & 0.857 & 0.009 & 3.978 & 2 & 0.137 & 0.123 & 1.199 & 2 & 0.549 & 0.036 \\
\hline $\begin{array}{l}\text { Number of } \\
\text { novel ideas }\end{array}$ & 2.376 & 2 & 0.305 & 0.074 & 6.247 & 2 & $0.044^{*}$ & 0.195 & 0.152 & 2 & 0.927 & 0.004 \\
\hline $\begin{array}{l}\text { Number of } \\
\text { feasible } \\
\text { ideas }\end{array}$ & 1.636 & 2 & 0.441 & 0.051 & 3.831 & 2 & 0.147 & 0.112 & 0.513 & 2 & 0.774 & 0.016 \\
\hline $\begin{array}{l}\text { Number of } \\
\text { relevant } \\
\text { ideas }\end{array}$ & 1.427 & 2 & 0.490 & 0.045 & 6.065 & 2 & $0.048^{*}$ & 0.189 & 1.871 & 2 & 0.392 & 0.058 \\
\hline
\end{tabular}

Nevertheless, there was a significant difference in fluency for the topic $2(H(2)=6.065$, $\left.p=0.048, \varepsilon^{2}=0.190\right)$ (see Table 3). A Dunn's post-hoc pairwise comparisons test displayed a significantly higher score for experts $($ mean $=12.6$, standard deviation $=$ 4.41) than for ordinary users $($ mean $=8.18$, standard deviation $=4.38)$, and for precursory users $($ mean $=13.9$, standard deviation $=6.32)$ than for ordinary users $($ see Figure 7). 


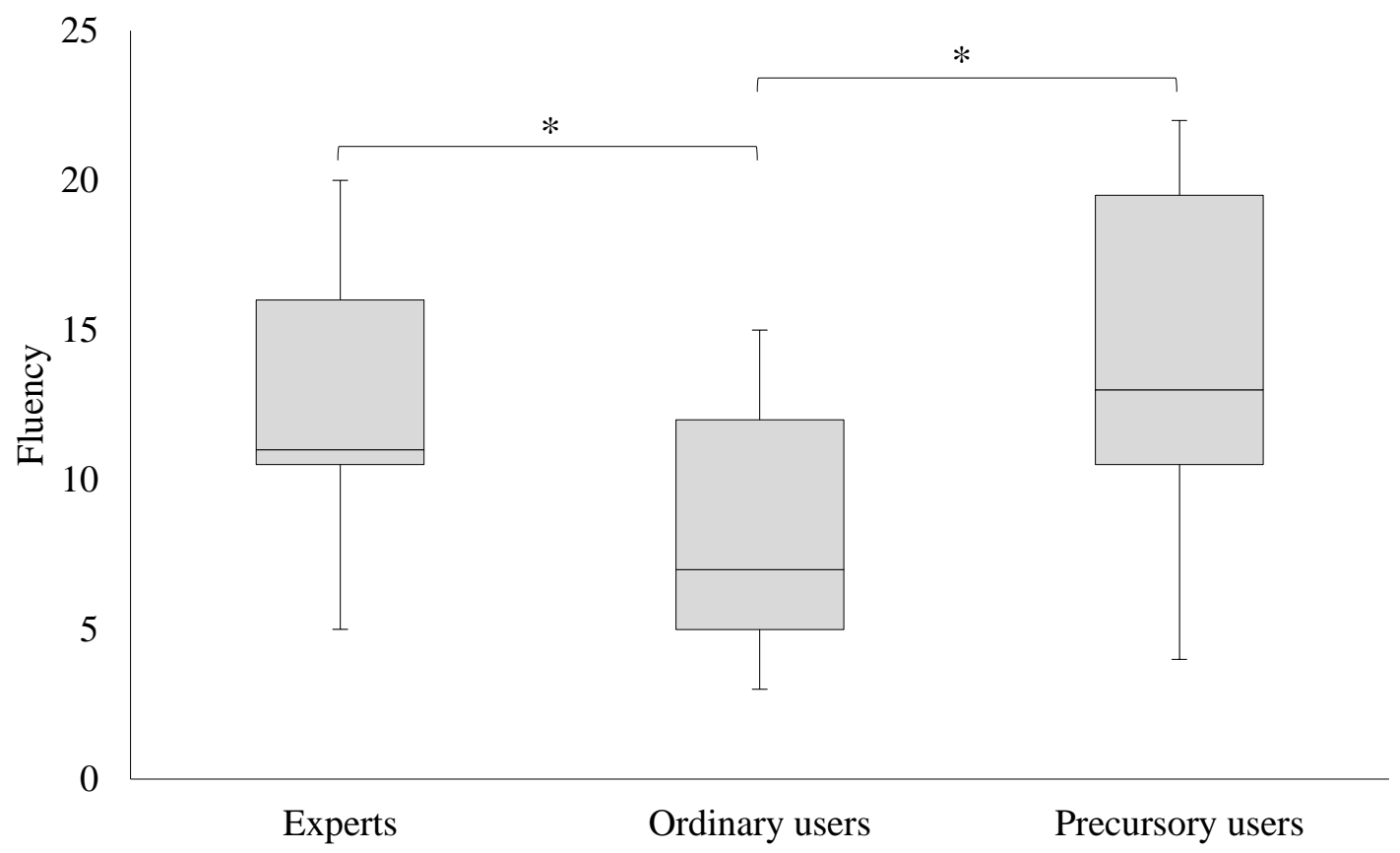

Figure 7: Fluency box plot (minimum, first quartile, median, third quartile and maximum) for the topic (2) Energy system management $(* p<.05)$.

We also observed a significant difference in number of novel ideas for the topic $2(H$ (2) $=6.247, p=0.044, \varepsilon^{2}=0.195$ ) (see Table 3). A Dunn's post-hoc pairwise comparisons test displayed a significantly higher number of novel ideas for experts (mean $=7.00$, standard deviation $=2.37)$ than for ordinary users $($ mean $=4.82$, standard deviation $=$ $1.99)$, and for precursory users $($ mean $=8.36$, standard deviation $=3.88)$ than for ordinary users (see Figure 8). 


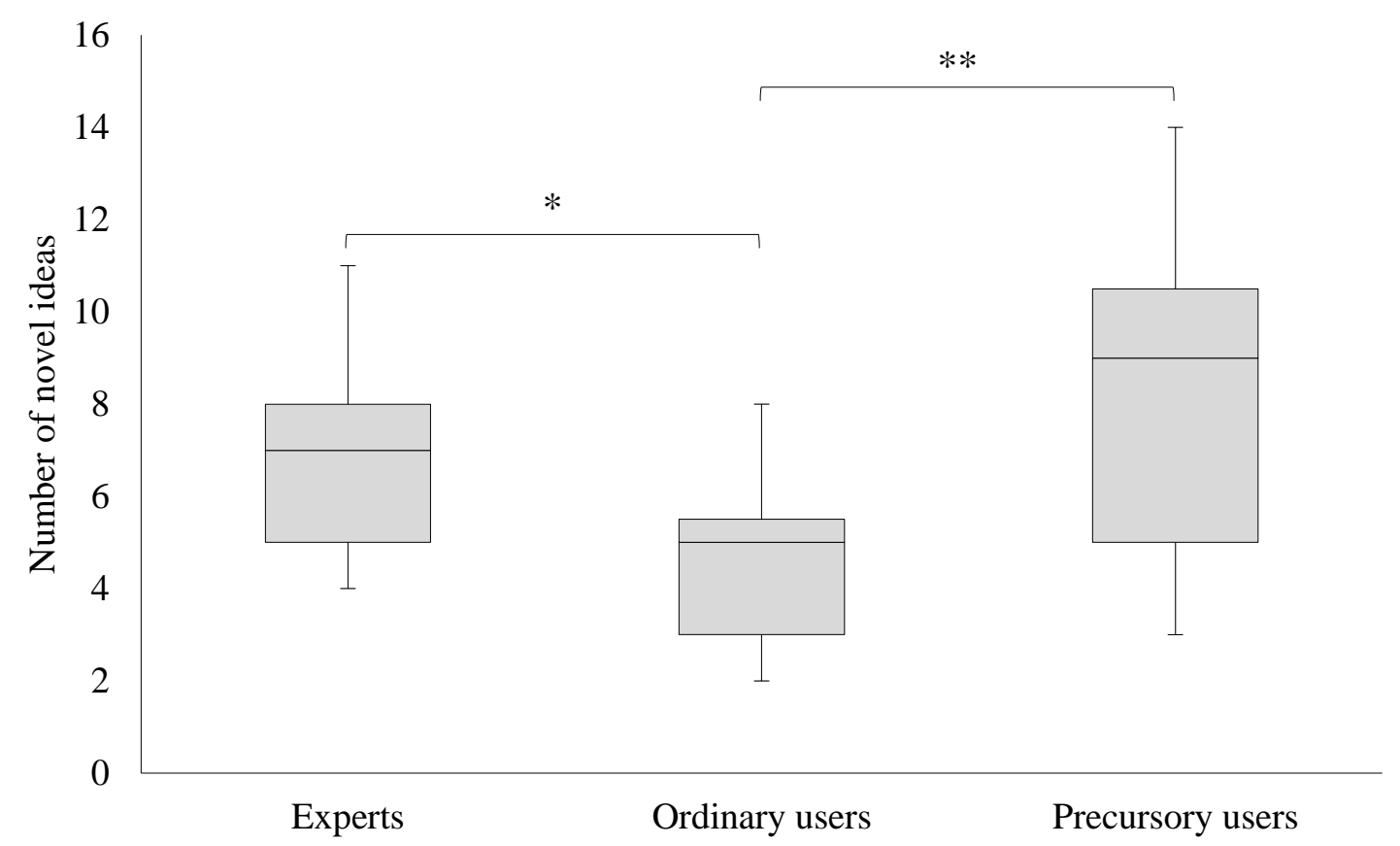

Figure 8: Number of novel ideas box plot (minimum, first quartile, median, third quartile and maximum) for the topic (2) Energy system management ( $* p<.05$, ** $p<.01)$.

Lastly, our analysis revealed a significant difference in number of relevant ideas for the topic $2\left(H(2)=6.065, p=0.048, \varepsilon^{2}=0.189\right)$ (see Table 3). A Dunn's post-hoc pairwise comparisons test displayed a significantly higher number of relevant ideas for experts $($ mean $=12.6$, standard deviation $=4.41)$ than for ordinary users $($ mean $=8.18$, standard deviation $=4.38)$, and for precursory users $($ mean $=13.9$, standard deviation $=6.32)$ than for ordinary users (see Figure 9). 


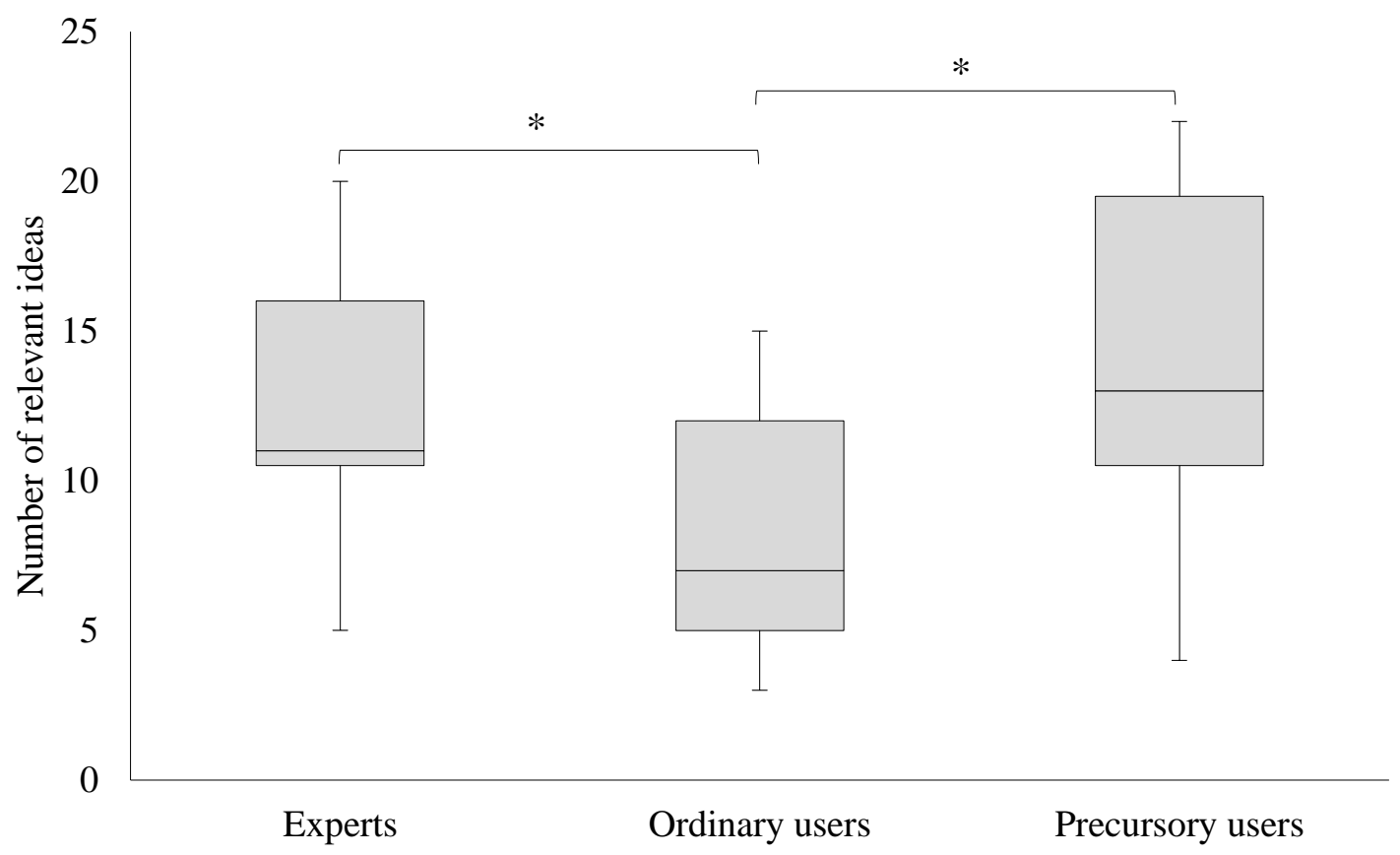

Figure 9: Number of relevant ideas box plot (minimum, first quartile, median, third quartile and maximum) for topic (2) Energy system management ( $* p<.05)$.

Thus, experts and precursory users mention more ideas and with a greater creativity in terms of both novelty and relevance. Although these results were limited to topic (2) Energy system management, they are consistent with our hypotheses that experts and precursory users may generate more ideas in their interview than ordinary users (H1.2), and that these ideas might be more novel (H1.4) and relevant (H1.6). However, our results do not lead us to conclude in favour of our hypotheses concerning originality (H1.3) and feasibility (H1.5).

\section{Discussion}

This study combined lexical analysis and needs idea analysis to compare the contribution of precursory users to experts and ordinary users to the need's analysis and anticipation phase. 


\subsection{Findings and limitations}

Lexical analysis has shown that the discourse of precursory users is richer and more original than that of experts and ordinary users. Indeed, precursory users evoke more lexical clusters and more lexical clusters which they are the only ones to evoke. It should be noted that experts nevertheless present a richer discourse than ordinary users. We also note that the discourse of experts refers more to lexical clusters related to professional expertise, while the discourse of precursory users refers more to lexical clusters related to uses and personal experience. In this respect, they are the only ones to address the installation of the energy system, the relationship to society and the state, and energy system management. These results suggest that experts and precursory users have an elaborate representation of the field. This representation is based on different types of knowledge: professional knowledge for experts and experience-based knowledge for precursory users. Moreover, precursory users do not simply have a discourse on the activity that is more important than experts and ordinary users, they have a discourse on activities that are not mentioned by others, suggesting that they are the only ones who experience and have knowledge of these activities.

Needs ideas analysis showed that experts and precursory users came up with more ideas, more new ideas and more relevant ideas than ordinary users. They therefore have the capacity to produce a large quantity of ideas, and to produce ideas that are not trivial and that apply well to the target area. However, these results are limited to the topic (2) Energy system management. We can explain this result by the fact that this topic corresponds to the least common and experienced activity, it is also the least detailed activity in the literature. This topic is therefore the one which is the most forwardlooking. Furthermore, the lexical analysis reveals that precursory users are the only ones to significantly mention energy system management in their interviews, which indicates that they are the only ones to experiment this activity. 
The limits that we see for this study are that the tools used for the need's analysis and anticipation do not vary (needs anticipation interview), and that the study was only carried out on one applied field (energy for housing). It would therefore be beneficial to reproduce this study in other contexts of applications and by varying the tools used, to generalize our findings.

\subsection{Practical implication for needs analysis and anticipation}

Our results indicate that experts and precursory users are more valuable than ordinary users in the need's analysis and anticipation phases. They are responsible for a richer and original speech and needs ideas. It appears that precursory users and experts are holders of what can be called a "prospective expertise" (Brangier et al., 2019): they have considerable knowledge of a field and they are able to go beyond this knowledge to imagine a future of this field, in our case to imagine needs that do not yet exist.

The inclusion of precursory users in the need's analysis phase makes it possible to overcome the difficulties associated with insufficient representations of the future and emerging artifacts by ordinary users. Moreover, and contrary to experts, it allows access to "real" future needs that are part of premature activities, and to future needs that are certainly hypothetical, but which are based on a representation linked to the experience of activity and artefact related to the field. Thus, it is possible to identify future needs related to emerging activities and artifacts, but also to identify the quality of the user experience. However, we argue that it is also important to include both experts and ordinary users in the analysis and anticipation phase of future needs. Indeed, while the inclusion of precursory users allows the identification of future user needs from an experience centred perspective, the inclusion of experts may allow the inclusion of ideas that are relevant to the challenges and changes in the field and that are not visible outside the relevant professional spheres. Based on our results, the inclusion of ordinary 
users does not seem to be useful for anticipating future needs. However, their inclusion may help to better understand current needs, to identify the barriers users face when they wish to move on to new activities or artefacts, and to assess users' perceptions of new activities and artefacts. Precursory users, experts and ordinary users therefore offer different contributions to this phase of anticipating needs (see Table 4).

\section{Table 4}

Contributions of ordinary users, precursory users and experts to the need's analysis and anticipation phase.

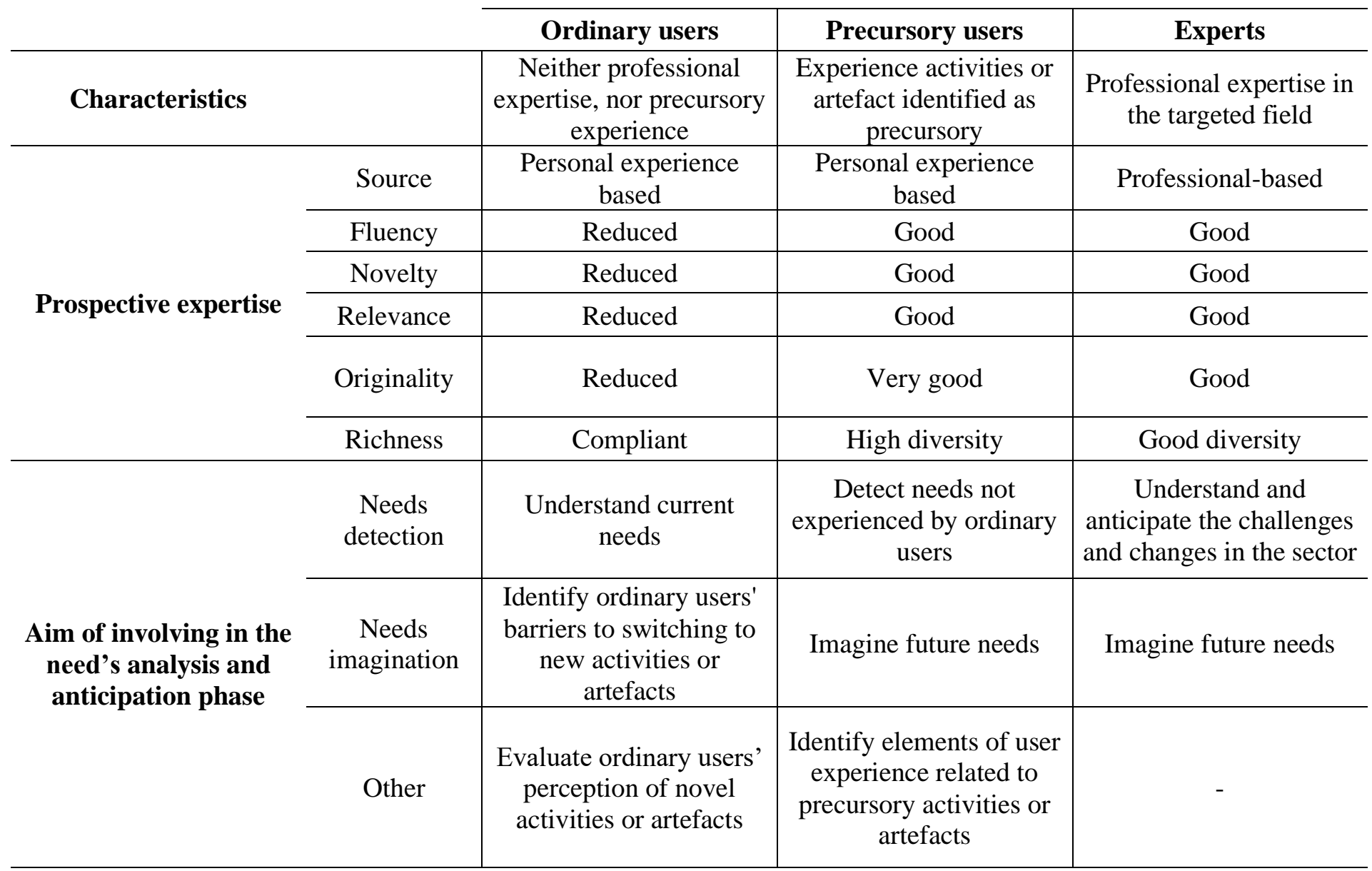

\subsection{Applied implication in the energy field}

The data collected during this study are to be used in the ULHyS project

(Université de Lorraine Hydrogen Sciences and technologies). The objective is to provide a description of presents and futures needs, activities and experiences related to energy for housing, to generate preliminary ideas related to future energy systems 
integrating hydrogen energy in the home. In doing so this study attempts to respond to the criticism made by Delzendeh et al. (2017), which indicates that humans are not part of "energy design" even though they are a crucial factor in energy systems.

\section{Conclusion}

Ergonomics is increasingly exposed to issues of innovation and future. Activity analysis provides insight into possible human, technical and organizational choices and potentially guides designers in their search for new ideas. However, activity-oriented ergonomics does not respond sufficiently to the identification of needs that do not yet exist.

The purpose of this study was to identify the specific contribution of ordinary users, precursory users and experts to the need's analysis and anticipation phase. Our assumption was that precursory users and experts would be better at generating novel needs ideas adapted to the context than ordinary users, given that they are known to have deep knowledge of the applied domain. We also assumed that their speech would be different, because they rely on different expertise.

For this we have conducted 36 needs anticipation interviews with ordinary users, precursory users and experts.

Our results indicate that experts and precursory users are more beneficial than ordinary users in anticipating needs. It therefore seems relevant to include both precursory users and experts in the need's analysis and anticipation phase, as they bring a different form of expertise: professional expertise - which makes it possible to grasp the major issues in the field - and experience-based expertise - which makes it possible to grasp the issues related to the actual activity. This expertise enables them to develop and identify future user needs at an early stage. The inclusion of precursory users also 
makes it possible to detect needs that concern activities that are not yet experienced by ordinary users.

Ergonomics plays an increasing role in innovation in the sense that it tends to develop user research upstream of design. In this way, the ergonomist also becomes a stimulator of new ideas. This implies that ergonomics must define intervention practices in the very early stages of a project which increase both creativity and future projection and involve the individuals who are best at these.

\section{Acknowledgment}

We would like to thank all those who took part in this study. We also warmly thank Clement COLIN for his participation and the fruitful discussions. This work was supported partly by the French PIA project « Lorraine Université d'Excellence », reference ANR-15-IDEX-04-LUE.

\section{Author contributions}

The Corresponding Author is A. Martin. M.F. Agnoletti and E. Brangier participated in the design of the study, provided critical feedback and helped shape the research. M.F. Agnoletti and E. Brangier participated in the financing of the study. A. Martin wrote the protocol, carried out data collection and data analysis. A. Martin took the lead in writing the manuscript. M.F. Agnoletti and E. Brangier supervised the whole project. We confirm that the manuscript has been read and approved by all named authors and that there are no other persons who satisfied the criteria for authorship but are not listed. We further confirm that the order of authors listed in the manuscript has been approved by all of us. 


\section{Disclosure statement}

The authors declare that they have no competing interests.

\section{References}

Anastassova, M. (2006). L'analyse ergonomique des besoins en amont de la conception de technologies émergentes. Université René Descartes.

Anastassova, M., \& Mayora-Ibarra, O. (2009). Elicitation of User Requirements for Mobile Interaction with Visual and RFID Tags: A Prototype-Based Exploratory Study. In M. Kurosu (Ed.), Human Centered Design (Vol. 5619, pp. 159-166). Springer Berlin Heidelberg. https://doi.org/10.1007/978-3-642-02806-9_19

Anastassova, M., Mégard, C., \& Burkhardt, J-M, J.-M. (2007). Prototype Evaluation and User-Needs Analysis in the Early Design of Emerging Technologies. In J. A. Jacko (Ed.), Human-Computer Interaction. Interaction Design and Usability (Vol. 4550, pp. 383-392). Springer Berlin Heidelberg. https://doi.org/10.1007/978-3-540-73105-4_42

Barré, J., Buisine, S., \& Aoussat, A. (2018). Persona logical thinking: Improving requirements elicitation for multidisciplinary teams. CoDesign, 14(3), 218-237. https://doi.org/10.1080/15710882.2017.1301959

Bastien, J.-M. C., Brangier, É., Dinet, J., Barcenilla, J., Michel, G., \& Vivian, R. (2009). The Expert Community Staff: An Innovative Method for Capturing End-users' Needs. 374-377.

Blaise, G., \& Glachant, M. (2019). Quel est l'impact des travaux de rénovation énergétique des logements sur la consommation d'énergie? La Revue de l'énergie, 646, 46-60. 
Bonnardel, N. (2012). Designing future products: What difficulties do designers encounter and how can their creative process be supported? Work, 41, 52965303. https://doi.org/10.3233/WOR-2012-0020-5296

Bonnardel, N., \& Pichot, N. (2020). Enhancing collaborative creativity with virtual dynamic personas. Applied Ergonomics, 82, 102949. https://doi.org/10.1016/j.apergo.2019.102949

Bonnin, M. (2016). Habitable et confortable modeles culturels, pratiques de l'habitat et pratiques de consommation d'energie en logement social et coproprietes. Université Paris Ouest.

Bourgeois-Bougrine, S., Latorre, S., \& Mourey, F. (2018). Promoting creative imagination of non-expressed needs: Exploring a combined approach to enhance design thinking. Creativity Studies, 11(2), 377-394. https://doi.org/10.3846/cs.2018.7184

Bovay, C. (Ed.). (1987). L'Energie au quotidien: Aspects sociologiques et éthiques de la consommation d'énergie. Labor et Fides.

Brangier, É., Barcenilla, J., \& Robert, J.-M. (2017). Prospective ergonomics and innovative ideas in the early stages of design projects. In A. Zunjic (Ed.), Ergonomic Design and Assessment of Products and Systems (pp. 47-68). Nova Science Publishers.

Brangier, É., Brangier, B., Marache-Francisco, C., Kopp, S., \& Clausse, J. (2019). An Interview Process to Anticipate Future Needs: First Analysis of an Approach to Explore Future User Experiences in the Fields of Business Travel and Tourism. In S. Bagnara, R. Tartaglia, S. Albolino, T. Alexander, \& Y. Fujita (Eds.), Proceedings of the 20th Congress of the International Ergonomics Association 
(IEA 2018) (Vol. 824, pp. 718-729). Springer International Publishing. https://doi.org/10.1007/978-3-319-96071-5_76

Brangier, É., \& Robert, J.-M. (2014). L’ergonomie prospective: Fondements et enjeux. Le travail humain, 77(1), 1. https://doi.org/10.3917/th.771.0001

Brem, A., Bilgram, V., \& Gutstein, A. (2018). Involving Lead Users in Innovation: A Structured Summary of Research on the Lead User Method. International Journal of Innovation and Technology Management, 15(03), 1850022. https://doi.org/10.1142/S0219877018500220

Buisine, S., Boisadan, A., \& Richir, S. (2018). L’innovation radicale par la méthode de l'utilisateur extraordinaire. Psychologie du Travail et des Organisations, 24(4), 374-386. https://doi.org/10.1016/j.pto.2017.11.001

Colin, C., \& Martin, A. (2019). Improving mental time travel abilities to support the collection of needs: A pilot study. In O. Broberg \& R. Seim (Eds.), Proceedings of the 50th Nordic Ergonomics and Human Factors Society Conference (NES 2019) (pp. 86-93).

D’Argembeau, A. (2016). La pensée future épisodique: Entre simulation et contexte autobiographique. Revue de neuropsychologie, 8(1), 55-59. https://doi.org/10.3917/rne.081.0055

D’Argembeau, A., \& Van der Linden, M. (2012). Predicting the phenomenology of episodic future thoughts. Consciousness and Cognition, 21(3), 1198-1206. https://doi.org/10.1016/j.concog.2012.05.004

Dean, D. L., Hender, J. M., Rodgers, T. L., \& Santanen, E. L. (2006). Identifying Quality, Novel, and Creative Ideas: Constructs and Scales for Idea Evaluation1. Journal of the Association for Information Systems, 7(10), 646-698. 
Delzendeh, E., Wu, S., Lee, A., \& Zhou, Y. (2017). The impact of occupants' behaviours on building energy analysis: A research review. Renewable and Sustainable Energy Reviews, 80, 1061-1071. https://doi.org/10.1016/j.rser.2017.05.264

Faullant, R., Schwarz, E. J., Krajger, I., \& Breitenecker, R. J. (2012). Towards a Comprehensive Understanding of Lead Userness: The Search for Individual Creativity: TOWARDS A COMPREHENSIVE UNDERSTANDING OF LEAD USERNESS. Creativity and Innovation Management, 21(1), 76-92. https://doi.org/10.1111/j.1467-8691.2012.00626.x

Frederiks, A. J., Englis, B. G., Ehrenhard, M. L., \& Groen, A. J. (2019). Entrepreneurial cognition and the quality of new venture ideas: An experimental approach to comparing future-oriented cognitive processes. Journal of Business Venturing, 34(2), 327-347. https://doi.org/10.1016/j.jbusvent.2018.05.007

French, M. J. (1985). Conceptual Design for Engineers. Springer Berlin Heidelberg. https://doi.org/10.1007/978-3-662-11364-6

Guibourdenche, J. (2013). Préoccupations et agencements dans les contextes d'activité domestique Contribution à la conception de situations informatiques diffuses, appropriables et énergétiquement efficaces. Université de Lyon.

Guibourdenche, J., Vacherand-Revel, J., Fréjus, M., \& Haradji, Y. (2015). Analyse de contextes d'activité domestique pour la conception de systèmes diffus énergétiquement efficients. Activites, 12(1). https://doi.org/10.4000/activites.994

Hassenzahl, M. (2018). The Thing and I: Understanding the Relationship Between User and Product. In M. Blythe \& A. Monk (Eds.), Funology 2 (pp. 301-313). Springer International Publishing. https://doi.org/10.1007/978-3-319-682136_19 
Hassenzahl, M., Diefenbach, S., \& Göritz, A. (2010). Needs, affect, and interactive products - Facets of user experience. Interacting with Computers, 22(5), 353362. https://doi.org/10.1016/j.intcom.2010.04.002

Hassenzahl, M., Wiklund-Engblom, A., Bengs, A., Hägglund, S., \& Diefenbach, S. (2015). Experience-Oriented and Product-Oriented Evaluation: Psychological Need Fulfillment, Positive Affect, and Product Perception. International Journal of Human-Computer Interaction, 31(8), 530-544. https://doi.org/10.1080/10447318.2015.1064664

Hollis-Hansen, K., O’Donnell, S. E., Seidman, J. S., Brande, S. J., \& Epstein, L. H. (2019). Improvements in episodic future thinking methodology: Establishing a standardized episodic thinking control. PLOS ONE, 14(3), e0214397. https://doi.org/10.1371/journal.pone.0214397

International Organization for Standardization. (2019). ISO 9241-210:2019— Ergonomie de l'interaction homme-système-Partie 210: Conception centrée sur l'opérateur humain pour les systèmes interactifs. Association française de normalisation.

Irish, M., \& Piguet, O. (2013). The Pivotal Role of Semantic Memory in Remembering the Past and Imagining the Future. Frontiers in Behavioral Neuroscience, 7. https://doi.org/10.3389/fnbeh.2013.00027

Jansson, D. G., \& Smith, S. M. (1991). Design fixation. Design Studies, 12(1), 3-11. https://doi.org/10.1016/0142-694X(91)90003-F

Jaruzelski, B., Staack, V., \& Goelhe, B. (2014). Proven Paths to Innovation Success. Strategy, 77.

Lahoual, D., \& Fréjus, M. (2013). La maîtrise de l'énergie comme nouveau champ pour l'ergonomie: Un exemple avec l'analyse de l'activité de particuliers producteurs 
d'énergie solaire. 48ème congrès international de la Société d'Ergonomie de Langue Française, Paris.

Lilien, G. L., Morrison, P. D., Searls, K., Sonnack, M., \& Hippel, E. von. (2002). Performance Assessment of the Lead User Idea-Generation Process for New Product Development. Management Science, 48(8), 1042-1059. https://doi.org/10.1287/mnsc.48.8.1042.171

Loup-Escande, E., Burkhardt, J.-M., Christmann, O., \& Richir, S. (2014). Needs' elaboration between users, designers and project leaders: Analysis of a design process of a virtual reality-based software. Information and Software Technology, 56(8), 1049-1061. https://doi.org/10.1016/j.infsof.2014.04.008

Loup-Escande, E., Burkhardt, J.-M., \& Richir, S. (2013). Anticiper et évaluer l'utilité dans la conception ergonomique des technologies émergentes: Une revue. Le travail humain, 76(1), 27. https://doi.org/10.3917/th.761.0027

Miloyan, B., McFarlane, K. A., \& Suddendorf, T. (2019). Measuring mental time travel: Is the hippocampus really critical for episodic memory and episodic foresight? Cortex, 117, 371-384. https://doi.org/10.1016/j.cortex.2019.01.020

Nelson, J., Buisine, S., \& Aoussat, A. (2013). Anticipating the use of future things: Towards a framework for prospective use analysis in innovation design projects. Applied Ergonomics, 44(6), 948-956. https://doi.org/10.1016/j.apergo.2013.01.002

Nguyen, C., \& Cahour, B. (2014). Véhicule électrique et gestion de son autonomie: Une approche prospective ancrée dans l'expérience vécue. Le travail humain, 77(1), 63-89. https://doi.org/10.3917/th.771.0063

Noël, X., Saeremans, M., Kornreich, C., Jaafari, N., \& D’Argembeau, A. (2017). Future-oriented mental time travel in individuals with disordered gambling. 
Consciousness and Cognition, 49, 227-236.

https://doi.org/10.1016/j.concog.2017.02.006

Norman, D. A. (1988). The psychology of everyday things. Basic Books.

Pahl, G., Beitz, W., Feldhusen, J., \& Grote, K. H. (Eds.). (2007). Engineering design: A systematic approach (3rd ed). Springer.

Partala, T., \& Kallinen, A. (2012). Understanding the most satisfying and unsatisfying user experiences: Emotions, psychological needs, and context. Interacting with Computers, 24(1), 25-34. https://doi.org/10.1016/j.intcom.2011.10.001

Petiot, J.-F., \& Yannou, B. (2004). Measuring consumer perceptions for a better comprehension, specification and assessment of product semantics. International Journal of Industrial Ergonomics, 33(6), 507-525. https://doi.org/10.1016/j.ergon.2003.12.004

Revell, K. M. A., \& Stanton, N. A. (2017). Mental models: Design of user interaction and interfaces for domestic energy systems. CRC Press, Taylor \& Francis Group.

Robert, J.-M., \& Brangier, É. (2012). Prospective ergonomics: Origin, goal, and prospects. Work, 41, 5235-5242. https://doi.org/10.3233/WOR-2012-0012-5235

Robert, J.-M., Maldar, M., Taraghi, M., \& Seffah, A. (2019). User Innovation, Lead Users and Crowdsourcing for the Design of New Products and Services: Why, What and How? In S. Bagnara, R. Tartaglia, S. Albolino, T. Alexander, \& Y. Fujita (Eds.), Proceedings of the 20th Congress of the International Ergonomics Association (IEA 2018) (Vol. 824, pp. 730-743). Springer International Publishing. https://doi.org/10.1007/978-3-319-96071-5_77 
Schacter, D. L., Addis, D. R., \& Buckner, R. L. (2007). Remembering the past to imagine the future: The prospective brain. Nature Reviews Neuroscience, $8(9)$, 657-661. https://doi.org/10.1038/nrn2213

Sidler, O. (2011, January). De la conception à la mesure, comment expliquer les écarts? ? Congress Evaluate low consumption buildings efficiency, Angers.

Spérandio, J.-C. (2001). Critères ergonomiques de l'assistance technologiques aux opérateurs. JIM’2001 : Interaction Homme - Machine \& Assistance, Metz.

Torrance, E. P., Ball, O., \& Safter, T. (1966). The Torrance Test of Creative Thinking. Bensenville, Illinois: Scholastic Testing Service.

Trope, Y., \& Liberman, N. (2003). Temporal construal. Psychological Review, 110(3), 403-421. https://doi.org/10.1037/0033-295X.110.3.403

Trope, Y., \& Liberman, N. (2010). Construal-level theory of psychological distance. Psychological Review, 117(2), 440-463. https://doi.org/10.1037/a0018963

Tuch, A. N., Trusell, R., \& Hornbæk, K. (2013). Analyzing users' narratives to understand experience with interactive products. Proceedings of the SIGCHI Conference on Human Factors in Computing Systems - CHI '13, 2079. https://doi.org/10.1145/2470654.2481285

Visser, W., \& Falzon, P. (1988). Recueil et analyse de l'expertise dans une activité de conception: Questions de méthode. Psychologie Française, 33(No. Spécial 'Psychologie de l'Expertise'), 133-138.

von Hippel, E. (1986). Lead Users: A Source of Novel Product Concepts. Management Science, 32(7), 791-805. https://doi.org/10.1287/mnsc.32.7.791

Wolff, M., Burkhardt, J.-M., \& de la Garza, C. (2005). Analyse exploratoire de “ points de vue ": Une contribution pour outiller les processus de conception. Le travail humain, 68(3), 253-286. https://doi.org/10.3917/th.683.0253 
Youmans, R. J., \& Arciszewski, T. (2014). Design fixation: Classifications and modern methods of prevention. Artificial Intelligence for Engineering Design, Analysis and Manufacturing, 28(2), 129-137.

https://doi.org/10.1017/S0890060414000043

Zélem, M., Gournet, R., \& Beslay, C. (2013). Pas de smart cities sans smart habitants. Les Cahiers Du Développement Urbain Durable, 15, 45-60. 